\title{
A Study of Interactional Metadiscourse in English Travel Blogs
}

\author{
Ying Huang, Huijian Wang, Junhong Tang \\ Baoding University, Baoding, China \\ Email: yinghebtu@163.com
}

How to cite this paper: Huang, Y., Wang, H. J., \& Tang, J. H. (2020). A Study of Interactional Metadiscourse in English Travel Blogs. Open Journal of Modern Linguistics, 10, 785-793.

https://doi.org/10.4236/ojml.2020.106048

Received: October 23, 2020

Accepted: November 28, 2020

Published: December 1, 2020

Copyright $\odot 2020$ by author(s) and Scientific Research Publishing Inc. This work is licensed under the Creative Commons Attribution International License (CC BY 4.0).

http://creativecommons.org/licenses/by/4.0/

(c) (i) Open Access

\begin{abstract}
With the development of tourism industry in internet plus era, travel blogs have become the main form of travel recording. Regarded as a valid device to intrude readers and to construct interaction between the writers and their readers, interactional metadiscourse is adopted widely. The study builds a corpus which consists of 30 English travel blogs. By calculating the occurrences and analyzing the functions of interactional metadiscourse, the study chooses qualitative and quantitative analysis to indicate how blogger writers communicate with the readers within narrative travel blogs and how they influence the reader's future travel experience by using typical interactional metadiscourse.
\end{abstract}

\section{Keywords}

Metadiscourse, Interactional Metadiscourse, English Travel Blogs

\section{Introduction}

With the increased level of people's life, tourism industry has apparently become prevailing and is thriving at a high speed. People in the $21^{\text {st }}$ century are eager to travel further and globally which leads to more accessible information relating to travel to appear prominently. Regarded as a discussion platform, travel blogs appeared for people to report unforgettable travel experiences together with their thoughts, impressions, emotions, perceptions and feelings that deserve recording. According to Banyai \& Glover (2012), travel blogs enable people to make social engagement much more easily and play an inevitable role in word-of-mouth exchange and communication. Based on Hyland's (2005a) model of interactional metadiscourse, the study makes research on interactional metadiscourse use in English travel blogs. By quantitative and qualitative analysis, the study reveals the occurrences of interactional metadiscourse and analyzes 
how they function on the realization of mutual interaction between the writer and the readers.

\section{Literature Review}

This part contains three aspects of contents. Firstly, it introduces previous studies on metadiscourse. Secondly, it discusses previous studies on interactional metadiscourse. At last, it illustrates some previous studies on travel blogs which shows there is not so much metadiscourse-oriented study on travel blogs in the field of linguistic studies.

\subsection{Previous Studies on Metadiscourse}

Zellig Harris firstly proposed "metadiscourse" in 1959 as an academic concept. Since then, so many linguistic scholars and experts have interpreted and analyzed metadiscourse in different directions and it is still arousing attention and has become the core of study in the field of applied linguistics. According to Hyland (2005a), metadiscourse appears as a tool expressing self-reflection to achieve mutual interaction within a text between the writer and the readers. $\mathrm{Xu}$ (2006) regards metadiscourse as linguistic device to achieve discourse organization, readers' expression and response to the discourse. Fu and Xu (2012) make a summary on the achievements of metadiscourse study within five years including five angles of contents: theoretical research, research methods, research models, categorization discussion and research field.

\subsection{Previous Studies on Interactional Metadiscourse}

Based on Crismore et al.'s (1993) taxonomy, Hyland (1998) classifies metadiscourse into two major categories: textual metadiscourse and interpersonal metadiscourse. In 2005, Hyland (2005b) suggests a different interpersonal model with the purpose to solve the existed problems in the former one, which adopted Thompson and Thetela's (1995) concepts of interactive and interactional features of interaction. In the same year, Hyland (2005a) analyzes the function of metadiscourse in 240 published academic discourses in constructing mutual interaction which divided metadiscourse into two dimensions: stance features and engagement features. According to Hyland's study on interactional metadiscourse, then Gillaerts \& Van de Velde (2010) make a study choosing a corpus of research article abstracts on interactional metadiscourse. Besides the former two broad dimensions: stance and engagement, Chinese scholar Fu (2012) make refined classification by proposing seven sub-categories including hedges, boosters, attitude markers, self-mentions, reader-inclusive pronouns, questions and directives and choose a corpus study by analyzing 220 job postings.

\subsection{Previous Studies on Travel Blogs}

In 2005, travel blogs began to arouse the attention of scholars all around the world depending on Kurashima et al.'s (2005) pioneering study. Then analyzing a corpus of 114 travel blogs in relation to trips to Austria, Wenger (2008) com- 
pares the differences and similarities between the blog posts and Austria's tourism markets, and analyzed negative and positive notions relating to Austria. Tussyadiah and Fesenmaier (2008) invoke the meanings assigned to different tourism products by analyzing bloggers' positive and negative feelings in narrative writings.

Generally speaking, in the field of discourse analysis, the number of study and analysis on travel blogs is not so much. It is clear that metadiscourse plays an important role in writing construction, so plenty of scholars conduct researches on the contribution of metadiscourse within discourse as a linguistic device and on the improvement of readability and quality of a text. Totally speaking, most scholars tend to choose academic discourse as corpus to make linguistic studies, so analyzing travel blogs from the perspective of discourse analysis opens a new research direction to some extent.

\section{Theoretical Analysis}

\subsection{Interactional Model of Metadiscourse}

By employing a functional approach in the field of linguistics, Hyland (2005b) classifies metadiscourse into two categories: interactive metadiscourse and interactional metadiscourse. In Hyland (2005b)'s opinion, metadiscourse emphasizes the realization of interpersonal functions which include evaluation, stance and engagement. On the basis of Hyland's interpersonal model and interactional metadiscourse, Hyland (2005a) puts forward a new model on analyzing the interaction between the writer and the readers in academic discourse which is relatively comprehensive and integrated in interaction examining. According to his classifications, the academic interactional metadiscourse is divided into two broad features: the stance features and the engagement features. Regarded as attitudinal rhetorical devices, stance resources incline to be writer-oriented and are primarily used to express the writer's evaluations and attitudes. Relatively speaking, the engagement resources are more reader-oriented and functioned to intrude readers into texts explicitly and directly with the aim to realize the interaction between the writer and the reader. Based on these two features, Hyland sub-categorizes them separately into nine sub-categories (Table 1).

\subsection{Stance Features}

According to Hyland's (2005a) introduction, the stance features are adopted for writers to present themselves and express attitude, commitment and judgment. Regarding stance features as writer-oriented linguistic devices, the writers usually express a textual voice and intrude their personal authority into the descriptions. According to Hyland's (2005a), stance features include four sub-categories:

Table 1. Hyland's interactional model of metadiscourse in academic discourse.

\begin{tabular}{ll}
\hline Stance features & Hedges, Boosters, Attitude markers, Self-mention \\
Engagement features & Reader pronouns, Directives, Questions, Shared knowledge, Personal asides
\end{tabular}


hedges, boosters, attitude markers and self-mentions in the model of interactional metadiscourse.

\subsubsection{Hedges}

Regarded as typical linguistic devices, hedges are mainly adopted to express the uncertainty of the writer within stance features. Hedges are usually represented by some typical words such as perhaps, possible, may, almost and etc. The use of hedges enables writers to withhold the whole commitment to a proposition instead of presenting a certain truth.

\subsubsection{Boosters}

Boosters are mainly adopted to increase certainty of an expression. Typical boosters represented by definitely, obviously, surely appear with high frequency in corpus in the form of adverbs, which decrease the uncertainty of a proposition and promote the writers' attitude and emotional expression to a greater extent.

\subsubsection{Attitude Markers}

Attitude markers are used to express writer's attitudes, affection and judgments explicitly and directly. Attitude verbs, modals and adjectives are the common forms for representation in English blogs represented by dislike, hate, fortunately, wonderful, remarkable, good and etc. in English blogs.

\subsubsection{Self-Mentions}

In English travel blogs, self-mentions appear indispensably as a powerful device to project the writers into discourse. The writers always use first person pronouns and possessive adjectives, such as $I$, me, we, our to emphasize the existence of themselves. With the appearance of self-mentions, bloggers seem to retell and describe his or her real travel experience to the potential readers face to face and share their internal emotions with readers.

\subsection{Engagement Features}

Relatively speaking of stance, engagement is a different dimension for writers to connect and interact with their readers by achieving the readers' presence and intruding them into the "dialogue" as an essential participant. According to Hyland's (2005a) characterization of engagement features, there exist five sub-categories as following described.

\subsubsection{Reader-Pronouns}

In order to realize the reader's presence definitely in texts, the writers always adopt reader-pronouns to achieve the desired effect. It is regarded as a symbol to achieve virtual and mutual communication with the readers in travel blogs. Reader pronouns are represented by you, your, we which play a role in connecting writer and readers together and enhance the mutual intimacy within blogs.

\subsubsection{Directives}

Directives are linguistic devices for writers to instruct and influence the readers' 
performance. By directives, the readers are recommended appointed action and influenced to look upon things in a specified way. The common directives usually refer to the imperative vocabularies, such as consider, note and imagine and so on. Functioning to tell potential tourists what should do or not and what need to be noticed, directives in travel blogs are mainly used to instruct readers to perform more physical acts.

\subsubsection{Questions}

Always followed by question marks, questions successfully attract readers' attention when they appear within a text. The common questions always offer the readers enough space to think about what the writer is talking about in which way to intrude the readers into the discoursal conversation. It is easy to some extent for readers to express their own curiosity on the writers' arguments in time.

\subsubsection{Shared Knowledge}

Shared knowledge contributes to the construction with readers for writers by presuming their own common beliefs, assigning them a role in argument creation and recognizing their contributions. It always appears in the forms of phrases and short sentences such as of course we know that..., it obviously reflects that..., it is universally acknowledged that... with the purpose to realize the above function.

\subsubsection{Personal Asides}

Personal asides contribute to the realization of addressing readers straightly by interrupting the argument and then making a comment on what has been argued. Since travel blogs contain the features of being narrative, it is rare for personal asides to express others' comments towards the blog description.

\section{Data Collection and Analysis}

\subsection{Data Collection}

The corpus includes 30 English travel blogs with 16419 tokens which were retrieved online from http://tripandtravelblog.com/ with the purpose to guarantee the authenticity and validity of the research data. The study adopts both quantitative analysis and qualitative analysis based on the corpus. Qualitative analysis refers to the functional analysis of interactional metadiscourse while quantitative analysis mainly calculates the frequency and distribution of interactional metadiscourse in the corpus.

\subsection{Quantitative Analysis of Interactional Metadiscourse}

Based on the analysis on the corpus of English travel blogs, it is easy to find that plenty of metadiscourse markers appear within the corpus for the construction of interaction between the writer and the reader. Table 2 reflects the total occurrences of each kind of interactional metadiscourse.

According to Table 2, it is obvious to figure out the stance features and engagement features do not share approximate occurrences of interactional metadiscourse 
Table 2. Total occurrence of interactional metadiscourse.

\begin{tabular}{ccc}
\hline Features & Occurrences & Proportion (\%) \\
\hline Hedges & 86 & 9.75 \\
Boosters & 171 & 19.39 \\
Attitude Markers & 122 & 13.83 \\
Self-mentions & 154 & 17.46 \\
Stance & 533 & 60.43 \\
Reader Pronouns & 254 & 28.80 \\
Directives & 54 & 6.12 \\
Questions & 14 & 1.59 \\
Shared Knowledge & 26 & 2.95 \\
Personal Asides & 1 & 0.11 \\
Engagement & 349 & 39.57 \\
Total & $\mathbf{8 8 2}$ & 100 \\
\hline
\end{tabular}

with stance occupying $60.43 \%$ and engagement $39.57 \%$ in the corpus. The reflected statistics suggests that English bloggers may desire to express their attitudes, affection and stances in their descriptions. Within stance dimension, it is easy to see that boosters, self-mentions and attitude markers rank the top 3 . Within engagement dimension, compared with the fewest personal asides (1), questions (14) and shared knowledge (26), reader pronouns are apparently prominent with the highest occurrences of 254, which is nearly five times more than directives with the occurrences of 54 . Analyzing the table as a whole, the first four sub-categories of interactional metadiscourse with the most occurrences are successively reader pronouns (254), boosters (171), self-mentions (154) and attitude markers (122) in which stance features occupy three quarter. Personal asides are the scarcest accounting for $0.11 \%$ of the whole interactional metadiscourse.

\subsection{Qualitative Analysis of Interactional Metadiscourse}

Table 2 suggests that stance and engagement markers are frequently used in English blogs for interaction construction. Since not all sub-categories share the uses with the same frequency, in this chapter we mainly discuss the first four sub-categories of interactional metadiscourse with higher distributions including reader-pronouns, boosters, self-mentions and attitude markers. The analysis aims to make a study on these linguistic devices by using the real examples and explain how the interaction between the writer and the reader is realized.

\subsubsection{Reader-Pronouns}

Reader-pronouns are used to address the reader directly and explicitly by which the readers are overtly brought into the discourse. The usual forms of reader-pronouns are second-person pronouns (you, your,) and we, our. The follow- 
ing examples (1) - (3) use reader-pronouns to construct a virtual and mutual dialogue with the readers and intrude the readers into the discourse explicitly and directly.

(1) Regardless of whether you are attracted by the rude and savage nature or you prefer to merge your aura with Mother Earth, you should do some hiking in the amaranth Red Rock Country for its unique beauty.

(2) Well, there are places in the world where you can live with less money and there are beautiful and exotic places that make you want to pack up and move, if not for life, at least for a while.

(3) Before you make your arrangements, I'd suggest you checked the weather forecast for the days you'll be spending there.

As can be seen from the italics, English bloggers use reader-pronouns to highlight the interaction with the reader by abundantly mentioning the readers in their writings.

\subsubsection{Boosters}

Boosters rank the second within all interactional metadiscourse in English corpus. As a kind of linguistic device indicating blogger's certainty toward the description of his or her travel experience, boosters can be symbolized by adverbials such as really, absolutely, definitely and so on. They mainly play a role in heightening the blogger's tone to emphasize and highlight his or her suggestions or statements. With the realization of boosters, the writers enable their descriptions to be more prominent and convincing to the potential tourists. Below are some examples.

(4) It was actually very touching, fitting of the romantic atmosphere. Finally we attended "A Heart of Kisses".

(5) And you absolutely must visit the church of St. Nicholas of Bari (the one with the green dome and bell tower). It is a jewel of Baroque architecture in Prague.

(6) The runway is at an altitude of 2900 meters above the sea level and is particularly popular with climbers, who use it as a starting point for the ascent to Everest.

All the italics show blogger's absolute certainty about his or her recommendation by heightening their tone.

\subsubsection{Self-Mentions}

First person singular form ( $I, m e, m y)$ and first person plural form (we, our, us) mainly appear with high frequency as main forms of self-mentions. For example:

(7) $M y$ attendant took me on the beach in Durres. There $I$ saw men with snakes entwined around their necks, men with bears on a leash, men with carts piled high with jackets, pools, balls, waterguns, and police cars along the shore.

(8) Mytrip to Albania lasted one week. After evaluating various opportunities $I$ decided to make the trip by plane and then rent a car. Booked a flight through an agency $I$ found on the internet with a representative in Tirana.

The overwhelming adoptions of self-mentions in above examples reveal that 
the bloggers' intention to describe travel experience from their own perspectives. As an active narrator, the blogger uses self-mentions to make self-representation explicitly.

\subsubsection{Attitude Markers}

According to Hyland (2005a), attitude markers function to indicate the writer's affection by conveying surprise, agreement, importance and so on. In English travel blogs, the bloggers endeavor to project and share his or her attitudes towards the travel experience itself by which the affective communication with potential tourists is realized. For example:

(9) In the summer it is a very pleasant experience to walk through the gardens.

(10) The wonderful climate and the perfect waves make this beach a destination for lovers of absolute surfing and skateboarding.

Pleasant in (9) functions as an adjective attitude marker to project the blogger's feelings of being happy to walk through the gardens. In (10), three adjectives (wonderful, perfect, absolute) are used as attitude markers to depict the satisfying conditions in Aruba. By adopting these discourse markers, the blogger expresses his compliment and satisfaction towards the destination. These adjective attitude markers also contribute to the construction of good impression of the beach.

\section{Conclusion}

Based on Hyland's (2005a) classification of interactional metadiscourse, this study chooses quantitative and qualitative analysis to calculate the occurrence frequency of interactional metadiscourse and to indicate how bloggers realize the interaction with readers. Based on the statistics, it is easy to figure out that interactional metadiscourse in English travel blogs is a kind of linguistic device with high adopted frequency which benefits the construction of mutual interaction of the bloggers and the readers. Among the nine sub-categories of interactional metadiscourse, reader pronouns (254) and boosters (171) make a definite leading with self-mentions (154) and attitude markers (122) following behind. The least one is personal asides (1) occupying $0.11 \%$ in all interactional metadiscourse. Generally speaking, stance features account for more than $60 \%$ compared with engagement features, which may illustrate that English bloggers incline to express their stance and attitudes towards authentic personal travel experiences and are more writer-oriented. To some extent, English bloggers are subjective and exoteric.

With the advent of the glorious era of tourism, a large number of travel discourses have appeared. The rise of the Internet age has prompted travel blogs to become the main expression of travel discourses. As an important means of introducing readers into discourses and building an interactive relationship between authors and readers, the application of interactive metadiscourse has become extremely widespread. According to Hyland (2005b), interactive metadiscourse refers to the way in which authors clearly express their opinions and 
guide readers to respond to the text. In order to realize the persuasive meaning of travel blogs, authors need to use interactive metadiscourse to establish reader interaction.

\section{Conflicts of Interest}

The authors declare no conflicts of interest regarding the publication of this paper.

\section{References}

Banyai, M., \& Glover, T. (2012). Evaluating Research Methods on Travel Blogs. Journal of Travel Research, 51, 267-277. https://doi.org/10.1177/0047287511410323

Crismore, A., Markkanen, R., \& Steffensen, M. (1993). Metadiscourse in Persuasive Writing: A Study of Texts Written by American and Finnish University Students. Written Communication, 10, 39-71. https://doi.org/10.1177/0741088393010001002

$\mathrm{Fu}, \mathrm{X}$. (2012). The Use of Interactional Metadiscourse in Job Postings. Discourse Studies, 14, 399-417. https://doi.org/10.1177/1461445612450373

Fu, X., \& Xu, J. (2012). Recent Developments in Metadiscourse Research Abroad. Contemporary Linguistics, 14, 260-271.

Gillaerts, P., \& Van de Velde, F. (2010). Interactional Metadiscourse in Research Article Abstracts. Journal of English for Academic Purposes, 9, 128-139. https://doi.org/10.1016/j.jeap.2010.02.004

Hyland, K. (1998). Persuasion and Context: The Pragmatics of Academic Metadiscourse. Journal of Pragmatics, 30, 437-455. https://doi.org/10.1016/S0378-2166(98)00009-5

Hyland, K. (2005a). Stance and Engagement: A Model of Interaction in Academic Discourse. Discourse Studies, 7, 173-191. https://doi.org/10.1177/1461445605050365

Hyland, K. (2005b). Metadiscourse: Exploring Interaction in Writing. London: Continuum.

Kurashima, T., Tezuka, T., \& Tannaka, K. (2005). Blog Map of Experiences: Extracting and Geographically Mapping Visitor Experience form Urban Blogs. In A. Ngu, M. Kitsuregawa, E. Neuhold, J. Chung, \& Q. Sheng (Eds.), Web Information Systems Engineering (pp. 496-503). New York: Springer. https://doi.org/10.1007/11581062_40

Thompson, G., \& Thetela, P. (1995). The Sound of One Hand Clapping: The Management of Interaction in Writing Discourse. Text, 15, 103-127.

https://doi.org/10.1515/text.1.1995.15.1.103

Tussyadiah, I., \& Fesenmaier, D. (2008). Marketing Place through First-Person Stories-An Analysis of Pennsylvania Road Tripper Blog. Journal of Travel \& Tourism Marketing, 25, 299-311. https://doi.org/10.1080/10548400802508358

Wenger, A. (2008). Analysis of Travel Bloggers' Characteristics and Their Communication. Journal of Vacation Marketing, 14, 169-176. https://doi.org/10.1177/1356766707087525

$\mathrm{Xu}, \mathrm{J}$. (2006). On the Scope and Classification of Metadiscourse. Contemporary Linguistics, 4, 345-353. 